\title{
Comparative Study between Atropine and Ketamine for Prevention of Oculocardiac Reflex in Children Undergoing Strabismus Surgery
}

FATMA E.I. ABOHARGA, M.Sc.; KAMAL AL-DEN A. HEIKL, M.D.; YASSER M. AMR, M.D. and MONA R. EL-GHAMRY, M.D.

The Department of Anesthesiology and Surgical Intensive Care, Faculty of Medicine, Tanta University, Tanta, Egypt

\begin{abstract}
Background: Oculucardiac Reflex (OCR) is the most common side effect during the strabismus surgeries. OCR is defined as a trigemino-vagal reflex, which may cause bradycardia, arrhythmias, and cardiac arrest after manipulating orbital structures.
\end{abstract}

Aim: Our aim is to compare the effect of atropine versus ketamine as a protector against oculocardiac reflex during strabismus surgery.

Material and Methods: This study was carried out on 111 children, 2-12 years, ASA I-II, scheduled for elective strabismus surgery under general anesthesia. Patients were randomized into three equal groups (37 patients in each group): Group C: Control Group (CG): Patient received $1 \mathrm{mg} / \mathrm{kg}$ propofol, $1 \mathrm{mic} / \mathrm{kg}$ fentanyl and $0.15 \mathrm{mg} / \mathrm{kg}$ cis-atracurium for induction of anesthesia. Group A: Atropine group (AG): 0.01 $\mathrm{mg} / \mathrm{kg}$ atropine, $1 \mathrm{mg} / \mathrm{kg}$ propofol, $1 \mathrm{mic} / \mathrm{kg}$ fentanyl and 0.15 $\mathrm{mg} / \mathrm{kg}$ cis-atracurium. Group K: Ketamine Group (kG): $1 \mathrm{mg} / \mathrm{kg}$ ketamine, $1 \mathrm{mic} / \mathrm{kg}$ fentanyl and $0.15 \mathrm{mg} / \mathrm{kg}$ cis-atracurium. The following parameters were compared between the 3 groups: Intraoperative hemodynamics, incidence \& severity of Oculocardiac Reflex (OCR), lenght of stay in post anesthesia care unit using modified aldert score, postoperative agitation using behavior score and incidence of Post-Operative Nausea $\&$ Vomiting (PONV) using neumeric rank score.

Results: Incidence \& severity of OCR and behavior score showed a significant decrease in groupK than group A \&C, while the mean arterial blood pressure showed insignificant difference at different tybe of operation. Lenght of stay in post Anesthesia Care Unit and post-operative nausea \& vomiting showed a significant increase in groupK than group A \& $C$.

Conclusions: In pediatric patients undergoing strabismus surgery, induction of anesthesia using $1 \mathrm{mg} / \mathrm{kg}$ ketamine showed significant decrease in incidence of OCR owing to its heamodynamic stability in comparison with atropine \& control groups which showed significant decrease in PONV.

Correspondence to: Dr. Fatma E.I. Aboharga,

The Department of Anesthesiology and Surgical Intensive Care, Faculty of Medicine, Tanta University, Tanta, Egypt
Key Words: Strabismus - Atropine - Ketamine-Oculocardiac reflex.

\section{Introduction}

STRABISMUS, or squint, is any misalignment of the visual axis. As a result the retinal image is not in corresponding areas of both eyes, which may result in diplopia in adult patients and can lead to amblyopia in childhood. Its the most common cause of pediatric ophthalmic surgery [1]. The orbital structures include six Extra Ocular Muscles (EOMs) which manipulated during strabismus surgery. Manipulation of the orbital structures can elicit the Oculocardiac Reflex (OCR) [2] .

In general, OCR is defined as a decrease in Heart Rate (HR) more than $20 \%$ from baseline after pressing the globe or occurrence of any type of dysrhythmia after manipulating orbital structures [3]. The afferent limb of reflex is from ciliary nerve to ciliary ganglion to ophthalmic division of the trigeminal nerve to the trigeminal sensory nucleus near the fourth ventricle. The efferent limb is by the vagus nerve to the heart [4].

OCR mostly cause sinus bradycardia but atrioventricular block, ventricular ectopy, ventricular fibrillation, or even asystole may occur so OCR may be fatal in pediatric patients [5]. OCR was exacerbated by orbital injection, hypercapnia, hypoxia, and inappropriate anesthetic depth [6]

Atropine increases firing of the Sinoatrial Node (SAN) and conduction through the Atrioventricular Node (AVN) of the heart, opposes the actions of the vagus nerve, blocks acetylcholine receptor sites [7] 
Ketamine an anaesthetic with both intrinsic analgesic and amnestic properties and protects airway reflexes. Ketamine activity has been suggested to be a result of the NMDA receptor antagonist property [8]

Ketamine also causes the sympatho-neuronal release of norepinephrine. It inhibits the efferent cardiac vagal drive by its central action, not baroreflex function. This central vagolysis is probably the cause of its positive chronotropic effects [9].

\section{Aim and objectives:}

The aim of the study is to compare the effect of atropine versus ketamie for prevention of OCR in children undergoing strabismus surgery.

\section{Material and Methods}

This prospective randomized single blind study was carried out in Tanta University Hospitals in Ophthalmic Department from September 2015 to February 2016, after obtaining the Research Ethics Committee Approval (approval code: (30522/09/ $15)$, an informed written consent was taken from patient guardians, the was carried out on 111 children of both sex, 2-12 years old, ASA I and II, scheduled for elective strabismus surgery of two extraocular muscles or more were enrolled into the present study. All the operation were done by the same surgeon. Refusal of patient guardians, history of cardiovascular disease, atropine fever or vasovagal response and history of traumatic eye injury were excluded from the study.

Patients were randomized into three equal groups by using sealed opaque envelop (37 patients in each group) according to the drugs used for induction of anesthesia: Group C: Control Group (CG): Patient received $1 \mathrm{mg} / \mathrm{kg}$ propofol, $1 \mathrm{mic} / \mathrm{kg}$ fentanyl and $0.15 \mathrm{mg} / \mathrm{kg}$ cis-atracurium. Group A: Atropine Group (AG): Patient received $0.1 \mathrm{mg} / \mathrm{kg}$ atropine, $1 \mathrm{mg} / \mathrm{kg}$ propofol, $1 \mathrm{mic} / \mathrm{kg}$ fentanyl and $0.15 \mathrm{mg} / \mathrm{kg}$ cis-atracurium. Group K: Ketamine Group (KG): $1 \mathrm{mg} / \mathrm{kg}$ ketamine, $1 \mathrm{mic} / \mathrm{kg}$ fentanyl and $0.15 \mathrm{mg} / \mathrm{kg}$ cis-atracurium.

Pre-operative assessment was done by: History taking, clinical examination, laboratory investigations including: $\mathrm{CBC}$, prothrombin time activity, liver and renal functions and electrolytes. Patients fasted according to ASA guidelines. On the arrival to O.R., the patients were attached to the monitor displaying the following: (Lead II ECG, pulse oximetry, NIBP and EtCO 2). An Intravenous (I.V) line was inserted by $22 \mathrm{G}$ cannula. Anesthesia has been induced with fentanyl $1 \mathrm{~g} / \mathrm{K}$ for all groups, propofol $1 \mathrm{mg} / \mathrm{Kg}$ for atropine and control groups, and ketamine $1 \mathrm{mg} / \mathrm{kg}$ for ketamine group, atropine $0.01 \mathrm{mg} / \mathrm{kg}$ for atropine group only, and cisatracurium $0.15 \mathrm{mg} / \mathrm{Kg}$ for all groups. A tracheal tube with suitable size has been placed orally three minutes after cis-atracurium administration, and anesthesia has been maintained with isoflurane 1$2 \%$ in oxygen, $0.03 \mathrm{mg} / \mathrm{kg}$ cis-atracurium increments, an infusion of $3-5 \mathrm{ml} / \mathrm{kg}$ ringer lactate solution has been administered as maintenance fluid. Intermittent Positive Pressure Ventilation (IPPV) with tidal volume $6 \mathrm{ml} / \mathrm{kg}$ and respiratory rate has been set to preserve $\mathrm{SpO} 2$ and $\mathrm{ETCO}_{2}$ within normal limits. By the end of surgery, inhalational anesthetic agents were discontinued, muscle relaxant was reversed using neostigmine $0.04 \mathrm{mg} / \mathrm{kg}$ and atropine $0.02 \mathrm{mg} / \mathrm{kg} \mathrm{IV}$, patients were extubated after regaining muscle power and protective reflexes and development of sufficient spontaneous ventilation. The patients were transferred to post anesthesia care unitand remained there until transferred to the surgery ward. All patient were premedicated with intravenous $0.1 \mathrm{mg} / \mathrm{kg}$ ondanosteron as an antiemetic 10min prior to the end of surgery.

Measurements: Demographic data (age, weight and sex). Heart rate, mean arterial blood pressure and were recorded at baseline before induction of anesthesia, 20sec before traction of EOMs, during traction of EOMs, 20sec after releasing traction of EOMs and at end of surgery (immediately before extubation). During the traction of Extraocular Muscle (EOM), the lowest Heart Rate (HR) was recorded and if it was below basal HR by $>10 \%$ beats/min, the anesthetist asked the surgeon to discontinue traction of Extraocular Muscle (EOM). If OCR was not recovered within 20 seconds by releasing tension on the muscle, atropine $0.02 \mathrm{mg} / \mathrm{kg}$ was injected intravenously, incidence of oculocardiac reflex; OCR defined as $>10 \%$ decrease in heart rate from base-line values obtained immediately after extraocular muscle manipulation, the incidence of OCR was recorded, severity of OCR was graded as mild if HR decreased by less than $20 \%$ of the baseline, and moderate if it decreased $20-30 \%$ of the baseline and severe if it decreased more than $30 \%$ of the baseline. Length of stay in Post Anesthesia Care Unit (PACU) was recorded by the Modified Aldrete Scoring System (Table 1), Post-operative agitation was evaluated immediately after tracheal extubation using behavior score [11] ( $1=$ sleeping, $2=$ awake and calm, $3=$ irritable and crying, 4=inconsolable crying, 5= severe restlessness and disorientation purposelessly wanting to get out of the bed) and Post-Operative Nausea and Vomiting (PONV) was evaluated for 24 hours post-operatively via Numeric Rank Score 
$(\mathrm{NRS})(0=$ no nausea, $1=$ nausea, $2=$ vomiting once and $3=$ vomiting twice or more times) [12]

Table (1): Modified aldrete scoring system [10]

\begin{tabular}{|c|c|c|}
\hline Item & Structure & Points \\
\hline \multirow[t]{4}{*}{ Activity } & - Able to move volantirly or on cmmnd: & \\
\hline & 4 extremities & 2 \\
\hline & 2 extremities & 1 \\
\hline & 0 extremities & 0 \\
\hline \multirow[t]{3}{*}{ Respiration } & - Able to deep breath and couph freely. & 2 \\
\hline & - Dyspnea, shallow or limited breathing. & 1 \\
\hline & - Apneic. & 0 \\
\hline \multirow[t]{3}{*}{ Circulation } & $\cdot \mathrm{BP} \pm 20 \mathrm{mmHg}$ of preanesthetic. & 2 \\
\hline & - $\mathrm{BP} \pm 20-50 \mathrm{mmHg}$ of preanesthetic. & 1 \\
\hline & $\cdot \mathrm{BP} \pm 50 \mathrm{mmHg}$ of preanesthetic. & 0 \\
\hline \multirow[t]{3}{*}{ Consiousness } & • Fully awake. & 2 \\
\hline & - Arousabl e on calling. & 1 \\
\hline & - Not responding. & 0 \\
\hline \multirow[t]{3}{*}{$\mathrm{O} 2$ saturation } & $\begin{array}{l}\text { - Able to maintain } \mathrm{O} 2 \text { saturation } 92 \% \text { on } \\
\text { room air. }\end{array}$ & 2 \\
\hline & $\begin{array}{l}\text { - Needs } \mathrm{O} 2 \text { inhalation to maintain } \mathrm{O} 2 \\
\text { saturation } 90 \% \text {. }\end{array}$ & 1 \\
\hline & $\begin{array}{l}\text { - } \mathrm{O} 2 \text { saturation } 90 \% \text { even with } \mathrm{O} 2 \\
\text { supplementation. }\end{array}$ & 0 \\
\hline
\end{tabular}

A score $\leq 9$ is required for discharge.

N.B.:

BP: Blood Pressure. O2: Oxygen.

The sample size calculation is performed using EpI-Info 2002 software statistical package designed by World Health Organization (WHO) and by Centers for Disease Control and Prevention (CDC). The sample size is calculated as $\mathrm{N}>33$ with $10 \%$ variation based on the following considerations: $95 \%$ confidence limit, $80 \%$ power of the study.

Statistical presentation and analysis was conductedby SPSS V.24. Results were expressed as means \pm Standard Deviation (SD). Student paired $t$-test: For statistical analysis within the same group. Unpaired $t$-test: Used for comparison of parametric data (age, weight, HR, MAP and length of stay in PACU) between the three studied groups. Modified chi-square test for small numbers: For comparison between three groups as regards qualitative data (sex, incidence \& severity of OCR, post-operative agitation and post-operative nausea $\&$ vomiting). ANOVA test was used for comparison among different times in the same group in quantitative data. $p$-value $<0.05$ was considered significant.

\section{Results}

There was no statistical significant difference between the three groups as regards to demographic data (age, sex and weight) and MAP at different time of operation (Table 2) \& Fig. (2).

HR values showed statistical significant decrease in control group in comparison with ketamine \& atropine groups, only during traction of EOMs Fig. (1).

Only two patient who need I.V atropine to abolish resistant bradycardia in control group without significant difference with atropine $\&$ ketamine groups.

Incidence and severity of OCR showed significant decrease $(p<0.05)$ in ketamine group in comparison with Atropine \& control groups (Table 3 ).

There was statistically significant decrease in the post-operative agitation using behavior score in group $\mathrm{K}$ in comparison with group $\mathrm{A} \&$ group C (Table 3).

Length of stay in PACU and incidence of PONV showed significant increase in the ketamine group in comparison with atropine \& control groups (Tables 2,3).

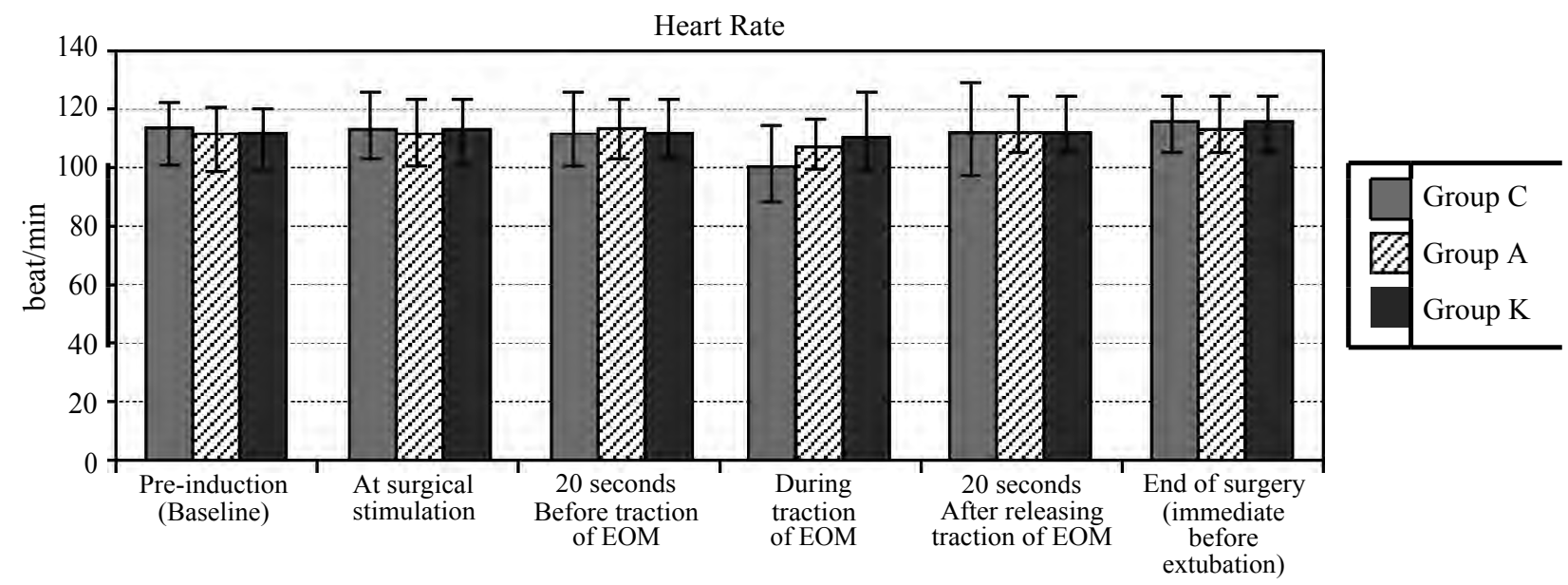

Fig. (1): Comparison of HR changes (beat $/ \mathrm{min}$ ) between the three groups. 


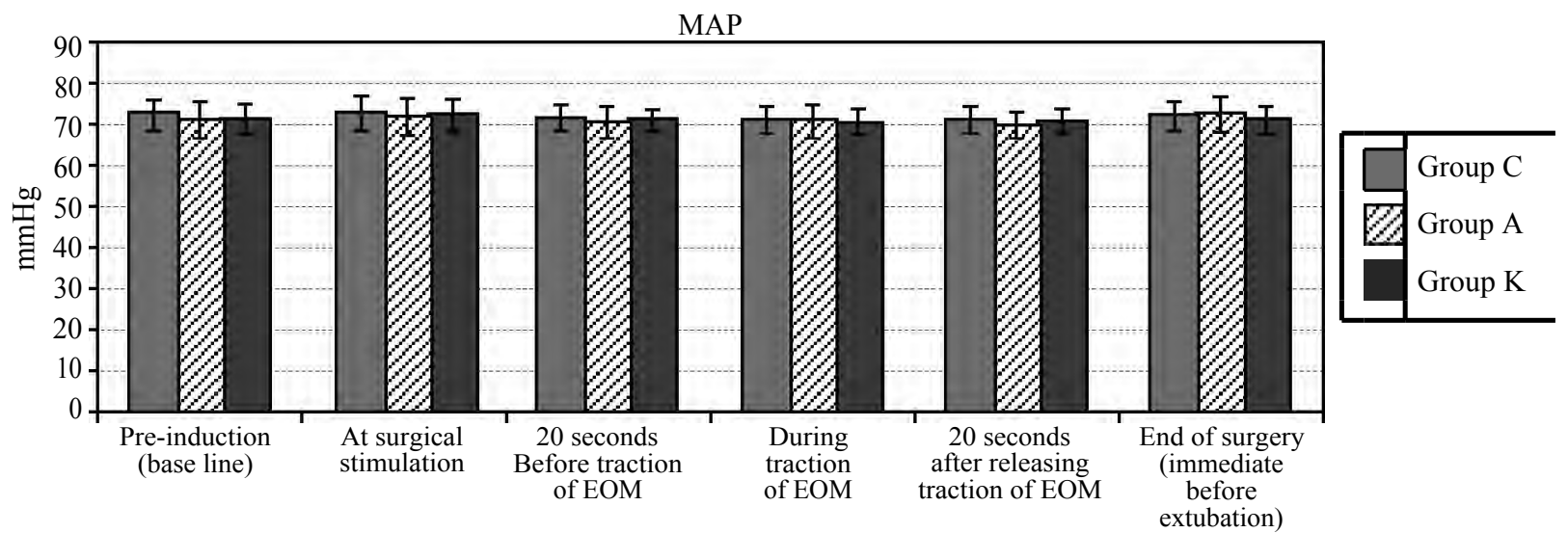

Fig. (2): Comparison of MAP changes ( $\mathrm{mmHg}$ ) between the three groups.

Table (2): Demographic data, base line heart rate, base line MAP, length of stay in PACU.

\begin{tabular}{lllllc}
\hline & Group C & Group A & Group K & Test & $p$-value \\
\hline Age (years) & $5.35 \pm 3.04$ & $5.65 \pm 2.78$ & $5.75 \pm 2.17$ & ANOVA & 0.907 \\
Weight & $18.59 \pm 6.01$ & $19.38 \pm 5.63$ & $19.05 \pm 6.19$ & ANOVA & 0.852 \\
Sex (M/F) & $15 / 22$ & $14 / 23$ & $12 / 25$ & Chi-square & 0.763 \\
Base line HR & $110.70 \pm 8.5$ & $108.97 \pm 8.81$ & $110.24 \pm 8.45$ & ANOVA & 0.670 \\
Base ilne MAP & $72.59 \pm 3.72$ & $71.41 \pm 4.38$ & $71.38 \pm 3.6$ & ANOVA & 0.316 \\
Length of stay in PACU & $15.16 \pm 1.26$ & $20.62 \pm 4.83$ & $27.73 \pm 5.03 *$ & ANOVA & $0.001 *$ \\
\hline *: Data presented as mean \pm SD. & & & &
\end{tabular}

Table (3): Incidence and severity of OCR (in the form of bradycardia or dysrrhythmia), post-operative agitation and post-operative nausea and vomiting.

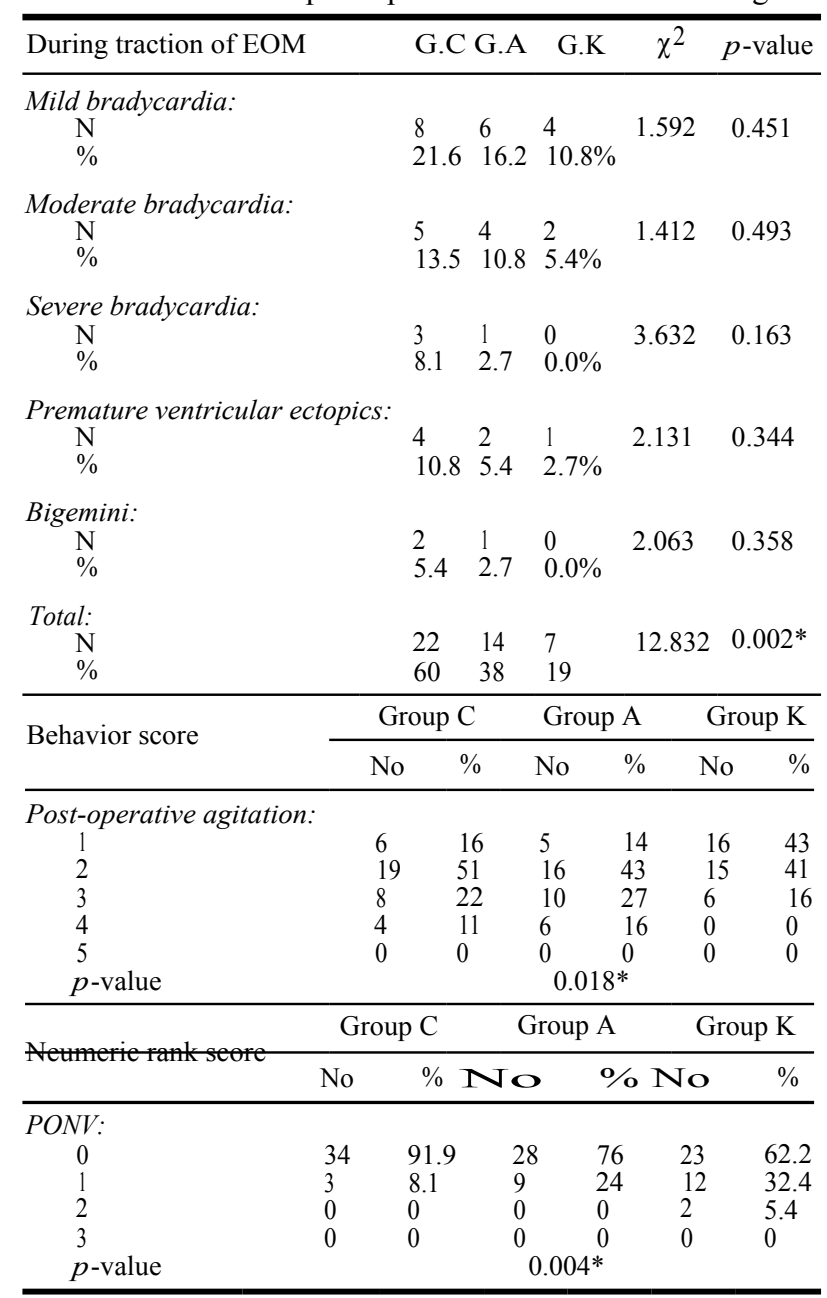

\section{Discussion}

Strabismus surgery is performed to restore binocular single vision and for cosmetic reasons (extensively in childhood). There are some undesired effects of the surgery such as Oculocardiac Reflex (OCR) postoperative anxiety, agitation and Post-operative Nausea and Vomiting (PONV). These effects are the most frequent complications secondary to surgery and causes distress in patients recovering from general anesthesia [13] .

As regards to the intraoperative hemodynamics the control group (group C) showed significant decrease in the Heart Rate (HR) following immediate traction of EOMs in comparison to the other two groups, which might be explained by the reduction of myocardial blood flow and myocardial oxygen consumption caused by propofol. In agreement with our study: Mizrak et al., [14] who studied the effect of intravenous infusion of Ketamine (K) and propofol $(\mathrm{P})$ anaesthesia in children undergoing strabismus surgery, they found that both heart rate and mean arterial blood pressure; in group $\mathrm{P}$ were significantly lower than in group $\mathrm{K}$ during intubation, incision, traction of extraocular muscles, extubation, and after extubation periods. Also, Safavi et al., [15] who compared the effects of thiopental, propofol or ketamine on the cardiovascular responses of the oculocardiac reflex during strabismus surgery and concluded that induction of anesthesia with ketamine is associated with the least cardiovascular changes induced by OCR 
during strabismus surgery in comparison with propofol and thiopental sodium.

As regards to mean arterial blood preassure, (MAP) was statistically insignificant between the three studied group in different time of operation. In agreement with our study, Mahajan et al., [16] Who studied the effect of ketamine and fentanyl in comparison with propofol in total intravenous anesthesia for short surgical procedures and concluded that both ketamine and fentanyl are equally safe and efficacious with propofol for short surgical procedures with no significant changes inMAP between the studied groups.

As regards to the Oculocardiac Reflex (OCR), the results showed that the incidence of OCR in group $\mathrm{K}$ was statistically lower in comparison with group A \& $\mathrm{C}$ ( $p$-value $<0.05)$ which might be attributed to the central sympathomimetic adrenergic effect of ketamine. In agreement with our results, Mizrak et al., [14]. The incidence of OCR during strabismus surgery among 60 children divided in two groups where ketamine is compared with propofol, they concluded that the incidence of OCR in group $\mathrm{K}$ was significantly lower compared to group P. Also, Choi et al., [17]. Who compared the induction by ketamine versus propofol induction and found that incidence of OCR was significantly decreased in the ketamine group. Moreover, Lee S.J. et al., [18]. Who studied the effect of single bolus of intravenous ketamine for anesthetic induction on oculocardiac reflex in children undergoing strabismus surgery and concluded that a single bolus of i.v. ketamine $1-2 \mathrm{mg} / \mathrm{kg}$ for anaesthetic induction results in a lower incidence of OCR than propofol when combined with sevoflurane for maintenance in children undergoing strabismus surgery.

In contrast with our results, Liu Y. et al., [19] Who investigated the advantages and disadvantages of sevoflurane-Nitrous oxide (N20) inhalation anesthesia and propofol-ketamine TIVA in children undergoing strabismus surgery. They found that, the incidence of OCR was significantly lower in the volatile group than those in the TIVA group. This might be explained by the cardio-depressant effect of propofol added to ketamine compared to $\mathrm{N}_{2} \mathrm{O}$ with its tendency to stimulate the sympathetic nervous system by increasing endogenous catecholamine levels.

As regards to the length of stay in PACU evaluated by using modified aldrete score and showed statistically longer recovery time in ketamine group compared to atropine \& control groups
( $p$-value $<0.001$ ), this is most probably related to ketamine metabolism to an active metabolite norketamine with an elimination half-life of 2-3 hours. In agreement with our study, Jia-Yao Chen et al., [20]. Who compared the effects of dexmedetomidine, ketamine, and placebo on emergence agitation after strabismus surgery in children andconcluded that the time for resumption of mental orientation and time to discharge from PACU were longer in the dexmedetomidine and ketamine groups than in the placebo group. Similarly, Pierre et al., [21] Who investigated recovery from anaesthesia and incidence and intensity of post-operative nausea and vomiting following TIVA with Ketaminepropofol (KP) compared to Alfentanil-Propofol (AP), they concluded that a TIVA with KP did not reduce $\mathrm{PONV}$ when compared to $\mathrm{AP}$, but prolonged recovery.

As regard the behavior score (agitation), the ketamine group showed a significant decrease in in the behavior score in comparison to the other groups. In agreement with our study, Jia-Yao Chen et al., [20]. Who compared the effects of dexmedetomidine, ketamine, and placebo on emergence agitation after strabismus surgery in children and concluded that ketamine appear to prevent postoperative agitation and pain after sevoflurane anesthesia for pediatric strabismus surgery. This results were concomitant with the study done by Mizrak et al., [14] who compared the use of ketamine infusion versus propofol infusion for strabismus surgery in children and concluded that more sedation and less agitation in the ketamine group. This results also supported by the study done by $\mathrm{Ka}-$ waraguchi et al., [22] who reported that an administration of ketamine $1 \mathrm{mg} / \mathrm{kg}$ after the induction of anesthesia and an instillation of ketamine 1 $\mathrm{mg} / \mathrm{kg} / \mathrm{hr}$ during operation in a pediatric strabismus surgery succeeded in decreasing emergence agitation.

As regards to the Post-Operative Nausea and Vomiting (PONV), results demonstrated that, the incidence of PONV for patients in ketamine group was statistically higher in comparison with atropine $\&$ control groups $(p$-value $<0.004)$. In agreement with our study, Thorp et al., [23]. Who reported that intravenous doses of ketamine-associated vomiting are not related to either the initial loading dose or the total dose but, the modest increase in receiving high cumulative doses. Also, Kranke et al., [24]. Who compared the post-operative nausea and vomiting by using isoflurane, enoflurane, sevoflurane and propofol infusion in strabismus operation and found that the incidence of PONV was significantly decreased in the propofol group 
in comparison to all other inhalational agents. Moreover, Altan A, et al., [25]. Who studied the effect of diazepam and atropine before strabismus surgery to prevent postoperative nausea and vomiting and concluded that diazepam and atropine sulfate premedication decreases nausea and vomiting after strabismus surgery.

\section{Conclusions:}

In pediatric patients undergoing strabismus surgery, induction of anesthesia with $1 \mathrm{mg} / \mathrm{kg}$ ketamine showed significant decrease in incidence of OCR owing to its hemodynamic stability in comparison with atropine and control groups which showed decreased incidence of PONV.

\section{Conflicts of interest:}

No conflicts of interest declared.

\section{Authors' contributions:}

All authors had equal role in design, work, statistical analysis and manuscript writing.

\section{References}

1- DEB K., SUBRAMANIAM R., DEHRAN M., TANDON R. and SHENDE D.: Safety and efficacy of peribulbar block as adjunct to general anaesthesia for paediatric ophthalmic surgery. Pediatric Anesthesia, 11 (2): 161-7, 2001.

2- DONLON J.V., DOYLE D.J. and FELDMAN M.A.: Anesthesia for eye, ear, nose, and throat surgery. In: Miller RD, Eriksson LI, Fleisher LA, Wiener-Kronish JP, Young WL (eds). Miller's anesthesia. 7 th ed. Philadelphia: Churchill Livingstone, 2378-84, 2009.

3- McGOLDRICK K.E. and GAYER S.I.: Anesthesia for ophthalmologic surgery. In: Barash PG, Cullen BF, Stoelting RK, Cahalan MK, Stock MC (eds). Clinical anesthesia. 6th Ed. Philadelphia: Lippincott Williams \& Wilkins, 1327-38, 2009.

4- RODGERS A. and COX R.G.: Anesthetic management for pediatric strabismus surgery: Continuing professional development. Canadian Journal of Anesthesia, 57 (6): 602-17, 2010

5- DELL R. and WILLIAMS B.: Anaesthesia for strabismus surgery: A regional survey. British Journal of Anaesthesia, 82 (5): 761-3, 1999.

6- HAHNENKAMP K., HONEMANN C.W., FISCHER L.G., DURIEUX M.E., MUEHLENDYCK H. and BRAUN U.: Effect of different anaesthetic regimes on the oculocardiac reflex during paediatric strabismus surgery. Pediatric Anesthesia, 10 (6): 601-8, 2000.

7- FAYON M., GAUTHIER M., BLANC V.F., AHRONHEIM G.A. and MICHAUD J.: Intraoperative cardiac arrest due to the oculocardiac reflex and subsequent death in a child with occult Epstein-Barr virus myocarditis. The Journal of the American Society of Anesthesiologists, 83 (3): 622-4, 1995.

8- TRUJILLO K.A., SMITH M.L., SULLIVAN B., HELLER C.Y., GARCIA C. and BATES M.: The neurobehavioral pharmacology of ketamine: Implications for drug abuse, addiction, and psychiatric disorders. ILAR Journal, 52 (3): 366-78, 2011.

9- MORRIS C., PERRIS A., KLEIN J., and MAHONEY P.: Anaesthesia in haemodynamically compromised emergency patients: Does ketamine represent the best choice of induction agent? Anaesthesia, 64 (5): 532-9, 2009.

10- MARSHALL, SCOTT I., and FRANCES CHUNG: "Discharge criteria and complications after ambulatory surgery." Anesthesia \& Analgesia, 88 (3): 508-17, 1999.

11- VISHNE T., AMIAZ R. and GRUNHAUS L.: Promethazine for the treatment of agitation after electroconvulsive therapy: A case series. The Journal of ECT, 21 (2): 11821, 2005.

12- APFEL C.C., KORTTILA K., ABDALLA M., KERGER H., TURAN A., VEDDER I. and RITVA J.: A factorial trial of six interventions for the prevention of postoperative nausea and vomiting. New England Journal of Medicine, 350 (24): 2441-51, 2004.

13- KIM H.K., YOON KC. and PARK Y.G.: Oculocardiac reflex during strabismus surgery. Journal of the Korean Ophthalmological Society, 44 (4): 896-903, 2003.

14- MIZRAK A., ERBAGCI I., ARICI T., OZCAN I., GANIDAGLI S., TATAR G., et al.: Ketamine versus propofol for strabismus surgery in children. Clinical Ophthalmology, 4: 673-9, 2010.

15- SAFAVI M. and HONARMAND A.: Comparison of effects of thiopental, propofol or ketamine on the cardiovascular responses of the oculocardiac reflex during strabismus surgery. Journal of Research in Medical Sciences, 12 (5): 246-50, 2007.

16- MAHAJAN R., SWARNKAR N. and GHASH A.: Comparison of ketamine and fentanyl with propofol in total intravenous anaesthesia: A double randomized clinical trial. Internet J. Anesth., 23: 239-43, 2009.

17- CHOI S.R., PARK S.W., LEE J.H., LEE S.C. and CHUNG C.J.: Effect of different anesthetic agents on oculocardiac reflex in pediatric strabismus surgery. Journal of Anesthesia, 23 (4): 489-93, 2009.

18- CHOI S., LEE S., KIM S., KIM J., KWON H., SHIN Y. and LEE K.: Single bolus of intravenous ketamine for anesthetic induction decreases oculocardiac reflex in children undergoing strabismus surgery. Acta Anaesthesiologica Scandinavica, 51 (6): 759-62, 2007.

19- LIU Y. and ZENG Q.: Sevoflurane-N2O inhalation anaesthesia with laryngeal mask airway and propofol-ketamine intravenous anaesthesia in strabismus surgery. Journal of Central South University Medical Sciences, 31 (1): 979, 2006.

20- CHEN J.Y., JIA J.E., LIU T.J., QIN M.J. and LI W.X.: Comparison of the effects of dexmedetomidine, ketamine, and placebo on emergence agitation after strabismus surgery in children. Canadian Journal of Anesthesia, 60 (4): 385-92, 2013.

21- ST PIERRE M., KESSEBOHM K., SCHMID M., KUNDT H. and HERING W.: Recovery from anaesthesia and incidence and intensity of postoperative nausea and vomiting following a Total Intravenous Anaesthesia (TIVA) with S-(+)-ketamine/propofol compared to alfentanil/ propofol. Der Anaesthesist, 51 (12): 973-9, 2002. 
22- KAWARAGUCHI Y., MIYAMOTO Y., FUKUMITSU K., TANIGUCHI A., HIRAO O. and KITAMURA S.: The effect of ketamine on reducing postoperative agitation after sevoflurane anesthesia in pediatric strabismus surgery. Masui the Japanese Journal of Anesthesiology, 51 (12): 1343-8, 2002

23- THORP A.W., BROWN L. and GREEN S.M.: Ketamineassociated vomiting: Is it dose-related? Pediatric Emergency Care, 25 (1): 15-8, 2009.

24- KRANKE P., APFEL C., PAPENFUSS T., METTERLEIN
T., SCHUSTER F., and MUELLENBACH R.: Nausea and vomiting after strabismus-surgery: A randomized comparison of isoflurane, enflurane, sevoflurane and propofol. The Open Clinical Trials Journal, 1 (1): 1-6, 2009.

25- ÖZCAN A.A., GÜNE S Y. and HACIYAKUPO GLU G.: Using diazepam and atropine before strabismus surgery to prevent post-operative nausea and vomiting: A randomized, controlled study. Journal of American Association for Pediatric Ophthalmology and Strabismus, 7 (3): 2102, 2003.

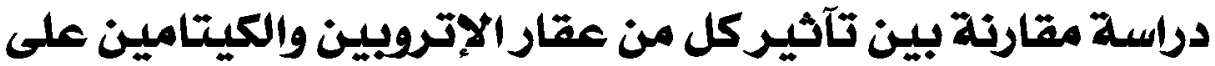

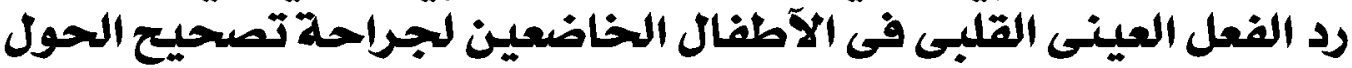

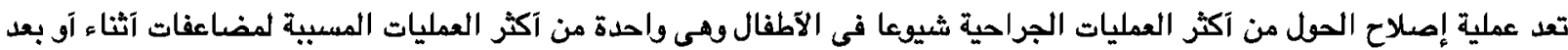

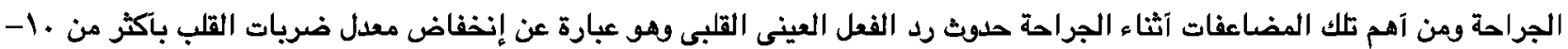

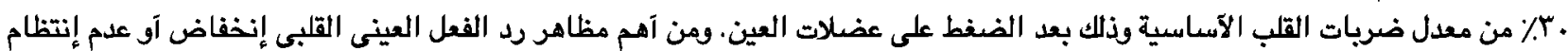

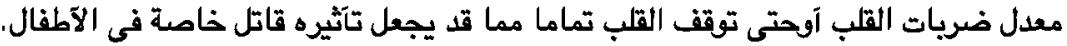

آيضا من المضاعفات التى قد تصدث بعد الجراحة إرتفاع معدل القيئ والفثيان وظهو الإنفعالات الشديدة على بعض الآطفال وطول البقاء

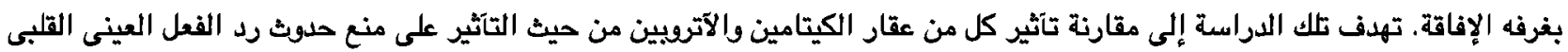

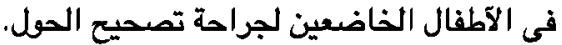

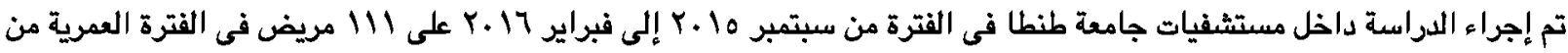

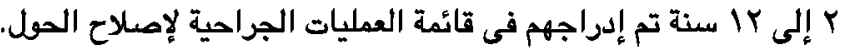

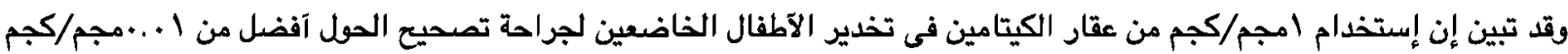
آتروبين وامجم/كجم بروبوفول من حيث تآثيره على حسث رد رد الفعل العينى القلبى آثناء الجراحة. 